\title{
Investigation of the Frequency of STOX1 Y153H Polymophism in Patients with Preeclampsia
}

\section{Evrim Suna Arikan Söylemez ${ }^{1 *}$, Dağıstan Tolga Arıöz , Müjgan Özdemir Erdoğan ${ }^{3}$, Fatih Çelik ${ }^{2}$ and Mariam Chkhikvadze ${ }^{2}$}

${ }^{1}$ Department of Medical Biology, Faculty of Medicine, Afyonkarahisar Health Sciences University, Afyonkarahisar, Turkey

${ }^{2}$ Department of Obstetrics and Gynecology, Faculty of Medicine, Afyonkarahisar Health Sciences University, Turkey

${ }^{3}$ Department of Medical Genetic, Faculty of Medicine, Afyonkarahisar Health

Sciences University, Turkey

*Corresponding Author: Evrim Suna Arikan Söylemez, Department of Medical Biology, Faculty of Medicine, Afyonkarahisar Health Sciences University,

Afyonkarahisar, Turkey.
Received: January 17, 2022

Published: January 24, 2022

(C) All rights are reserved by Evrim Suna

Arikan Söylemez., et al.

\begin{abstract}
Preeclampsia (PE), one of the most serious complications of pregnancy, is characterized by endothelial dysfunction and hypertension. Gastrointestinal complications of preeclampsia can occur and have the risk of being life-threatening for the mother and fetus. Genetic predisposition is a risk factor for PE. In this context, the genotype rates and allele frequencies of the STOX1 gene rs1341667 (Y153H) polymorphism in peripheral blood and placental tissues (decidua, umblical cord) of 25 PE patients and 25 healthy controls were examined by Light Cycler ${ }^{\circledR}$ Nano Real Time PCR Instrument (Roche Applied Systems). The STOX1 gene rs1341667 polymorphism exists in three different genotypes in humans: TT (wild type), TC (heterozygous) and CC (mutant). When the genotype frequencies of peripheral blood and placenta samples were compared between patients and controls, there was no difference (P > 0.05). The genotype results of the decidua and umblical cord samples, analyzed from the same placenta in all cases, were the same. There was no difference between allele frequencies of the patients and controls ( $>$ > 0.05). In our study, rs1341667 polymorphism was detected in peripheral blood and placental tissues of preeclamptic mothers. However, this polymorphism was also detected in healthy pregnant women peripheral bloods and their placental tissues. There was no difference between the frequencies of the $\mathrm{C}$ allele, which is the risk allele, in both blood and placental tissues of controls and PE patients. In this regard, we cannot support the view that the relevant polymorphism predisposes to preeclampsia. However, our study has small number of patients. This polymorphism needs to be analyzed in large populations.
\end{abstract}

Keywords: Preeclampsia; STOX1; Y153H; rs1341667; Polymorphism

\section{Abbreviations}

PE: Preeclampsia; STOX1: Stork Head Box 1; Y153H SNP: Y153H Single Nucleotide Polymorphism; rs1341667: Reference Single Nucleotide Polymorphism 1341667; TT: Timin-Timin; TC: TiminCytosine; CC: Cytosine-Cytosine; PCR: Polymerase Chain Reaction

\section{Introduction}

Preeclampsia (PE), one of the most serious complications of pregnancy, is characterized by endothelial dysfunction and hypertension. Although PE is one of the most important health problems affecting pregnant women, the genetic factors in the occurrence of 
the disease are still unclear. However, genetic predisposition is a risk factor for preeclampsia. It has been suggested that the placentally expressed STOX1 gene may be a candidate gene for preeclampsia. It has been suggested that the STOX1 Y153H SNP is present in all studied families who gave birth with preclamptic pregnancies. Studies show that preeclampsia is caused by the presence of the placenta during pregnancy and the symptoms disappear immediately after the placenta separates after delivery $[1,2]$.

Many studies point to the placenta as the primary cause of preeclampsia. Hypertensive diseases arising from placental defects affect more than $10 \%$ of pregnancies [3]. In the physiopathology of preeclampsia; as a result of insufficient uteroplacental vascularization, adequate blood supply to the developing fetus cannot be provided and fetoplacental hypoxia develops. This situation causes an imbalance between the secretion and metabolism of prostaglandins, endothelin and nitric oxide by the placenta and extraplacental tissues, and plays a role in the formation of hypertension, platelet activation and systemic endothelial dysfunction together with lipid peroxidation and other unspecified factors [4].

Preeclampsia is proteinuria and/or edema accompanying hypertension in pregnancy. In a patient with normal blood pressure at the beginning of pregnancy, a blood pressure of $140 / 90 \mathrm{mmHg}$ or higher after the 20th gestational week or an increase of $30 \mathrm{mmHg}$ in systolic pressure and $15 \mathrm{mmHg}$ in diastolic pressure compared to previous values are diagnostic for hypertension. Proteinuria, on the other hand, is the detection of $300 \mathrm{mg} / \mathrm{dl}$ or more protein in at least two urine samples taken 6 hours apart. Edema is common; it is especially evident on the back of the hand and face [5].

\section{Pathogenesis of preeclampsia}

The mechanisms underlying the pathogenesis of preeclampsia are multifactorial and there are many gaps regarding this issue [6]. Hypotheses such as immune maladaptation, endothelial dysfunction, oxidative stress, placental ischemia, angiogenesis and genetic conflict theories have been proposed to explain the etiology and pathogenesis of PE [7-9]. However, PE is a multisystem syndrome that includes genetic and environmental factors [10-12]. There are two stages involved in the development of PE; The first stage is weak placentation producing substances that interact with genetic and environmental structural factors, leading to the second stage of the clinical maternal syndrome.
The underlying mechanism for PE is an impaired placentation resulting from inadequate trophoblast invasion of the uterine spiral arteries. In addition to genetics playing a role, placental vascular insufficiency, micro-thrombosis and vasoconstriction seem to be the main causes in the pathophysiology of PE. Oxidative stress causes the release of factors such as antiangiogenic agents, proinflammatory cytokines, cell-free fetal DNA and exosomes into the maternal circulation, impairing maternal endothelial function, resulting in a systemic inflammatory response and hypertension. Other manifestations of the disease may include cardiac, pulmonary, haematological, renal, neurological and hepatic dysfunction $[8,13]$. Ersch., et al. [14] reported that feeding problems occurred in $46 \%$ of the preeclamptic group. Preeclampsia is associated with an increased relative risk for the development of end-stage kidney disease in the mother [15]. Beside, gastrointestinal complications of preeclampsia can occur and have the risk of being life-threatening for the mother and fetus [16].

\section{STOX1 gene and its role in preeclampsia}

The STOX1 (Storkhead Box 1) gene is a protein-coding gene. It is located in the 10q22.1 region. Diseases associated with the STOX1 gene include Pre-Eclampsia. Gene Ontology (GO) annotations for this gene include specific DNA binding to the RNA polymerase II regulatory region sequence. That is, the protein encoded by this gene can function as a DNA binding protein. Additionally, it is involved in the regulation of the levels of reactive oxidative species and reactive nitrogen species, and mitochondrial homeostasis in the placenta. Mutations in this gene are associated with preeclampsia/eclampsia 4 (PEE4) [17].

It has been suggested that the placentally expressed STOX1 gene may be a candidate gene for preeclampsia. Oudejans., et al. [18] presented evidence of an epigenetic phenomenon for preeclampsia in their study with Dutch women. van Dijk., et al. [19] suggested the STOX1 gene as a new imprinted gene for preeclampsia in their combined linkage analysis with candidate genes in the first trimester placenta. STOX1 is expressed in the early placenta and is preferentially expressed from the maternal allele.

STOX1 encodes a putative DNA-binding protein and is involved in the differentiation of trophoblasts. van Dijk., et al. [19] hypothesized that maternal transmission of the variant allele to the fetus triggers premature trophoblast differentiation resulting in pre- 
eclampsia and causes insufficient trophoblast invasion. It has been suggested that the paternal imprinted allele is silenced and the maternal allele is dominantly expressed. In addition, mutations in the STOX1 gene have been reported to predispose to preeclampsia. All preeclamptic women they studied had the STOX1 Y153H variant [19]. Van Dijk., et al. [20] defined that STOX1 functions in the fetal placenta by influencing trophoblast invasion, moreover, STOX1 Y153H SNP is present in all studied families who gave birth with pre-clamptic pregnancies.

Defective placenta formation, preeclampsia, and fetal growth retardation are common pregnancy disorders in humans. The presence of broad placental types in mammals has led to limited use of animal models for understanding human placental development. However, new directions, including three-dimensional organoids, stem cell culture systems, and single cell RNA sequencing, provide new perspectives in this field [21].

In this study, it was aimed to investigate the frequency of STOX1 rs1341667 (Y153H) polymorphism in preeclamptic and control group placentas and in blood samples of mothers.

\section{Materials and Methods}

Patients and ethics

All the placentas from the PE patients $(n=25)$ and healty mothers $(n=25)$ (aged 18-45) after giving birth were collected from the polyclinic of the Afyonkarahisar Health Sciences University, Faculty of Medicine, Department of Obstetrics and Gynecology. This study was approved by the Afyonkarahisar Health Sciences University Clinical Ethics Committee with the decision number 162 dated 01.06.2018. All patients have given their written consent for the use of their placenta and peripheral venous blood sample. The absence of a history of hypertension before pregnancy, the arterial blood pressure $\geq 14 / 90 \mathrm{mmHg}$ in two measurements at least six hours apart after the 20th week of pregnancy, and $\geq 0.3$ g protein excretion in the 24-hour urine were taken into account for the diagnosis of pre-eclampsia. Exclusion criterias for PE patients: no history of pre-pregnancy hypertension, no twin or multiple pregnancy, hydrops fesalis, mole hydatiform, renal disease, diabetes, heart disease, liver failure, malignancy, autoimmune disease. Exclusion criterias for healty mothers: no history of hypertension before and during pregnancy, no twin or multiple pregnancy, hydrops fesalis, hydatid mole, renal disease, diabetes, heart disease, liver failure, malignancy, autoimmune disease, no family history of pre-eclampsia.

\section{Collecting tissue and blood samples}

Within the scope of the study, approximately $1 \mathrm{~cm}^{3}$ samples were taken from the placental tissue expelled during normal birth or cesarean section, without any additional intervention and/or application of any additional medical agents other than those routinely required during the delivery process (decidua and umblical cord). The samples were stored at $-20^{\circ} \mathrm{C}$ until isolation of DNA. In addition, $2 \mathrm{cc}$ blood samples were taken from the volunteers in $5 \mathrm{cc}$ EDTA tube.

\section{Genomic DNA isolations and chemicals used for analysis}

Genomic DNA extractions of each tissue and blood samples were performed by using EZ-DNA total extraction kit (Biological Industries, Israel Beit Haemek Ltd, Cat. No: 20-600-50), RBC Lysis Solution (Biological Industries, Israel Beit Haemek Ltd, Cat. No: 01-888-1), HEPES Buffer (Biological Industries, Israel Beit Haemek Ltd, Cat. No: 03-025-1) according to the manufacturer's protocol. DNA quantity and purity were determined with Promega Quant Fluor E6090 (Promega, Madison, USA) and stored at $-20^{\circ} \mathrm{C}$ until use.

For the analysis of STOX1 gene rs1341667 polymorphism.

Light Snip Assay (TIB MOLBIOL, GmbH, Berlin, Germany, LOT: 48602001) was used. Kit includes DNase RNAz free water, Reagent Mix, FastStart DNA Master HybProbe (Roche Diagnostic).

\section{Genotyping}

Genotyping analyses of STOX1 gene rs1341667 polymorphism were completed with LightCycler ${ }^{\circledR}$ Nano Real Time PCR Instrument (Roche Applied Systems) using Real-Time PCR method. Preparation of the reaction mix is given in Table 1.

\begin{tabular}{|l|c|}
\hline Solution & Quantity per reaction \\
\hline $\mathrm{H}_{2} \mathrm{O}(\mathrm{DNaz}, \mathrm{RNaz}$ free) & $14.4 \mu \mathrm{l}$ \\
\hline Reaction mix & $1.0 \mu \mathrm{l}$ \\
\hline FastStart DNA Master HybProbe & $2.0 \mu \mathrm{l}$ \\
\hline $\mathrm{MgCl} 2(25 \mathrm{mM})$ & $1.6 \mu \mathrm{l}$ \\
\hline DNA & $1.0 \mu \mathrm{l}$ \\
\hline Last volume & $20 \mu \mathrm{l}$ \\
\hline
\end{tabular}

Table 1: Preparation of the Reaction Mix. 
The STOX1 gene rs1341667 polymorphism amplification protocol is as follows: After 10 minutes of denaturation at $95^{\circ} \mathrm{C}, 40$ cycles of denaturation at $95^{\circ} \mathrm{C}$ for 10 seconds, extension and amplification at $60^{\circ} \mathrm{C}$ for 10 seconds and at $72^{\circ} \mathrm{C}$ for 15 seconds were performed. Subsequently, melting curve analysis was performed at $95^{\circ} \mathrm{C}$ for 20 seconds, at $40^{\circ} \mathrm{C}$ for 20 seconds, and at $40^{\circ} \mathrm{C}$ for 30 seconds after rising to $85^{\circ} \mathrm{C}$.

\section{Results}

\section{Genotype data}

Genotype ratios and allele frequencies of STOX1 gene rs1341667 polymorphism were analyzed in peripheral blood and placental tissues (decidua, umblical cord) of 23 patients with preeclampsia and 23 healthy controls. Genotype analysis results of two cases belonging to each group could not be obtained. Sample genotype analysis curves are shown in Figure 1.

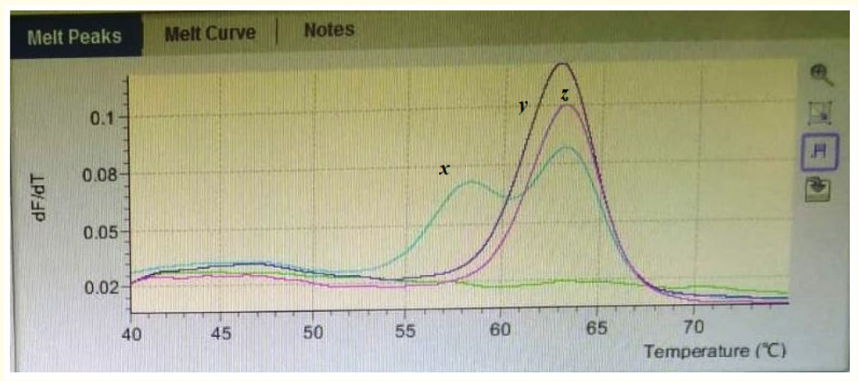

Figure 1. Results of blood and placental genotype analysis of the same preeclampsia patient.

X: Peripheral blood, Y: Decidua, Z: Umblical Cord.

\section{Genotype ratios of STOX1 gene rs1341667 polymorphism}

The STOX1 gene rs1341667 polymorphism exists in three different genotypes in humans: TT (wild type), TC (heterozygous) and CC (mutant).

In the control group, in 19 cases found as a result of peripheral blood DNA analysis; The number of individuals with the TT genotype was determined as $5(26.30 \%)$, the number of individuals with the TC genotype as 7 (36.84\%) and the number of individuals with the CC genotype as 7 (36.84\%) (Table 2). Analysis results could not be obtained from the blood samples of 4 control individuals. Considering the placental genotyping of the controls, the gen- otype results of the decidua and umblical cord samples analysed belonging to the same placenta were the same. The genotype of 6 placenta samples was determined as TT (31.58\%), the genotype of 9 placenta samples was determined as TC (47.37\%), and the genotype of 4 placenta samples was determined as CC (21.05\%) (Table 3 ). The genotype analysis results of 3 placenta samples could not be obtained.

In 16 cases found as a result of DNA analysis of peripheral blood in the preeclampsia patient group; The number of individuals with the TT genotype was 7 (43.75\%), the number of individuals with the TC genotype was 7 (43.75\%), and the number of individuals with the CC genotype was 2 (12.50\%) (Table 2). Analysis results could not be obtained from the blood samples of 7 patients. When the placental genotyping of the patients is examined, the genotype results of the decidua and cord samples analyzed belonging to the same placenta are the same. The genotype of 8 placenta samples was determined as TT (36.36\%), the genotype of 6 placenta samples was determined as TC (27.28\%), and the genotype of 8 placenta samples was determined as CC (36.36\%) (Table 3). Analysis result of 1 placenta sample could not be obtained.

\begin{tabular}{|l|c|c|}
\hline Genotype & Control group n = 19 & PE patient group n = 16 \\
\hline TT & $5(\% 26,30)$ & $7(\% 43,75)$ \\
\hline TC & $7(\% 36,84)$ & $7(\% 43,75)$ \\
\hline CC & $7(\% 36,84)$ & $2(\% 12,50)$ \\
\hline
\end{tabular}

Table 2: Genotype distribution of STOX1 gene rs1341667 polymorphism in peripheral blood samples.

\begin{tabular}{|l|c|c|}
\hline Genotype & Control group n = 19 & PE patient group $\mathbf{n}=\mathbf{2 2}$ \\
\hline TT & $6(\% 31,58)$ & $8(\% 36,36)$ \\
\hline TC & $9(\% 47,37)$ & $6(\% 27,28)$ \\
\hline CC & $4(\% 21,05)$ & $8(\% 36,36)$ \\
\hline
\end{tabular}

Table 3: Genotype distribution of STOX1 gene rs1341667 polymorphism in placental tissue samples.

\section{Allele frequencies of STOX1 gene rs1341667 polymorphism}

Frequency of $\mathrm{T}$ allele was 17 (44.74\%) and frequency of $\mathrm{C}$ allele was 21 (55.26\%) in DNA samples obtained from peripheral blood samples of control group, Frequency of T allele was 21 (65.63) and the frequency of the C allele was 11 (34.38\%) in DNA samples ob- 
tained from peripheral blood samples of PE patient group. T and C allele frequencies of STOX1 gene rs1341667 polymorphism were analyzed using the $\mathrm{x}^{2}$ test. There was no difference between the allelic frequencies of the two groups ( $\mathrm{P}>0.05)$ (Table 4).

The frequency of the T allele was 21 (55.26\%) and the frequency of the C allele was 17 (44.74\%) in DNA samples obtained from placental tissue samples of the control group, while the frequency of $\mathrm{T}$ allele was $22(\% 50)$ and the frequency of the $\mathrm{C}$ allele was 22 $(50 \%)$ in DNA samples obtained from placental tissue samples from the PE patient group. T and C allele frequencies of STOX1 gene rs1341667 polymorphism were analyzed using the $x^{2}$ test. There was no difference between the allele frequencies of the two groups (P > 0.05) (Table 5).

\begin{tabular}{|c|c|c|c|c|}
\hline Alle & $\begin{array}{c}\text { Control group } \\
n=38\end{array}$ & $\begin{array}{c}\text { PE patient } \\
\text { group } n=34\end{array}$ & $\mathbf{P}$ & OR \\
\hline $\mathrm{T}$ & $17(\% 44,74)$ & $21(\% 65$ & \multirow[t]{2}{*}{0.08} & \multirow{2}{*}{$\begin{array}{c}0.424 \\
(0.161-1.119)\end{array}$} \\
\hline $\mathrm{C}$ & $21(\% 55,26)$ & $11(\% 34,38)$ & & \\
\hline
\end{tabular}

Table 4: Distribution of allele frequencies of STOX1 gene rs1341667 polymorphism in peripheral blood samples.

\begin{tabular}{|c|c|c|c|c|}
\hline Allele & $\begin{array}{c}\text { Control group } \\
\mathbf{n}=\mathbf{3 8}\end{array}$ & $\begin{array}{c}\text { PE patient } \\
\text { group } n=44\end{array}$ & $\mathbf{P}$ & $\begin{array}{l}\text { OR }(95 \% \\
\text { CI) }\end{array}$ \\
\hline $\mathrm{T}$ & $21(\% 55,26)$ & $22(\% 50)$ & \multirow[t]{2}{*}{0.63} & \multirow{2}{*}{$\begin{array}{c}1.235 \\
(0.517-2.95)\end{array}$} \\
\hline $\mathrm{C}$ & $17(\% 44,74)$ & $22(\% 50)$ & & \\
\hline
\end{tabular}

Table 5: Distribution of allele frequencies of STOX1 gene rs1341667 polymorphism in placental tissue samples.

\section{Discussion}

Preeclampsia is a major cause of perinatal morbidity and mortality, and it is very strongly associated with fetal growth retardation. It has been suggested that the placentally expressed STOX1 gene may be a candidate gene for preeclampsia. Oudejans., et al. [18] presented evidence of an epigenetic phenomenon for preeclampsia in their study with Dutch women. van Dijk., et al. [19] suggested the STOX1 gene as a new imprinted gene for preeclampsia in their combined linkage analysis with candidate genes in the first trimester placenta. STOX1 is expressed in the early placenta and is preferentially expressed from the maternal allele. STOX1 encodes a putative DNA-binding protein and is involved in the differentiation of trophoblasts. On contrary to van Dijk., et al. 's studies,
Iglesias-Platas [22] suggested that STOX1 is not imprinted and is not likely to be involved in preeclampsia. Both suggestions are interesting.

In the study of Zhao., et al. [23], 65 women with preeclampsia were included in the study to investigate the relationship between STOX1 expression and the pathogenesis of early-onset preeclampsia. The expression and localization of STOX1 mRNA and protein in the placenta were evaluated by immunohistochemistry, RT-qPCR and Western blot consisting of three maternal groups. Expression of STOX1 in the placenta has been reported mainly in the cytoplasm of placental syncytiotrophoblasts, cytotrophoblasts, vascular endothelial and mesenchymal cells, with a few scattered in the cell nucleus. Staining intensity in the late-onset group was found to be similar to the control group. Positive expression rates of STOX1 protein in the early-onset group, late-onset group, and control group were $96.8 \%$ (30/31), 70.6\% (24/34) and 67.6\% (23/34) in the early-onset group, respectively. There was no statistical difference between the late-onset group and the control group in terms of STOX1 levels ( $\mathrm{P}=0.793)$. Expression levels of STOX1 mRNA were higher in the early-onset group than in the late-onset group $(\mathrm{P}<$ 0.05). There was no statistical difference between the late-onset group and the control group $(\mathrm{P}>0.05)$.

Van Dijk., et al. [19] determined a decreased progression in villus explants carrying the STOX1 HH genotype associated with preeclampsia. They suggested that this was consistent with the fact that the STOX1 HH genotype was associated with a decreased cellcell adhesion and a regressed differentiation towards an invasive phenotype. In addition, it has been suggested that STOX1 Y153H is effective in the invasion of extravilus trophoblast and plays a central role in the etiology of preeclampsia.

Similarly, Pınarbaşı., et al. [24] reported that STOX1 Y153H polymorphism is a risk factor for early-onset preeclampsia ( $\mathrm{P} \geq 0.03$ ), however, it is not a risk factor for late-onset preeclampsia. Berends., et al. [25] reported the $\mathrm{C}$ allele as the dominant allele in the Dutch population. In their study with 149 preeclampsia patients and 154 controls, the $\mathrm{C}$ allele frequency was $65 \%$ (genotype distribution; $43.5 \%$ CC, $43.5 \%$ CT and 13\% TT) in controls, while the C allele frequency was $64 \%$ (genotype distribution; $43 \%$ CC, $43 \%$ CT and $14 \%$ TT). It was determined that the frequency of $\mathrm{C}$ allele increased to $71 \%$ in those with a family history of preeclampsia. Contrary to these studies, another study found no relationship between STOX1 
Y153H polymorphism and preeclampsia in preeclamptic Finnish women [26]. Iglesias-Platas., et al. [22] also suggested that the STOX1 gene and Y153H SNP had no effect in their study.

\section{Conclusion}

In our study, rs1341667 (Y153H) polymorphism was detected in the peripheral blood and placental tissues of preeclamptic mothers. However, this polymorphism was also frequently detected in healthy pregnant women and their placental tissues. There was no difference between the frequencies of the $\mathrm{C}$ allele, which is the risk allele, in both blood and placental tissues of controls and PE patients. In this respect, we cannot support the view that the related polymorphism predisposes to preeclampsia, since there was no difference between the risk allele frequencies of controls and PE patients. The sample size of our study may be not large enough to reach statistically significant results. The absence of a family history of PE in our patients may be another limitation of our study. In this regard, we cannot support the view that the relevant polymorphism predisposes to preeclampsia. However, our study has small number of patients. This polymorphism needs to be analyzed in large populations.

\section{Acknowledgements}

This study was supported by Afyonkarahisar Health Sciences University BAP Commission with project number 19. KARIYER. 010.

\section{Conflict of Interest}

The authors declare no conflicts of interest.

\section{Bibliography}

1. Akiri G., et al. "Regulation of vascular endothelial growth factor (VEGF) expression is mediated by internal initiation of translation and alternative initiation of transcription". Oncogene 17.2 (1998): 227-236.

2. Redman CW., et al. "Latest advances in understanding preeclampsia". Science 308.5728 (2005): 1592-1594.

3. Sibai BM. "Thrombophilia and severe preeclampsia: time to screen and treat in future pregnancies?" Hypertension 46.6 (2005): 1252-1253.

4. Sibai BM. "Hypertension in pregnancy". The New England Journal of Medicine 327.10 (1992): 733-734.
5. ACOG practice bulletin. "Diagnosis and management of preeclampsi and eclampsia". Number 33, January 2002. American College of Obsteticians and Gynecologists. International Journal of Gynecology and Obstetrics 77.1 (2002): 67-75.

6. Baijnath S., et al. "The optimization of a chronic nitric oxide synthase (NOS) inhibition model of pre-eclampsia by evaluating physiological changes". European Journal of Obstetrics and Gynecology and Reproductive Biology 182.71 (2014): 5.

7. Powe CE., et al. "Preeclampsia, a disease of the maternal endothelium: the role of anti-angiogenic factors and implications for later cardiovascular disease". Circulation 123.24 (2011): 1-27.

8. Tomimatsu T., et al. "Preeclampsia: maternal systemic vascular disorder caused by generalized endothelial dysfunction due to placental antiangiogenic factors". International Journal of Molecular Sciences 20.4246 (2019).

9. Dekker G., et al. "Etiology of preeclampsia: an update". Journal of the Medical Association of Thailand 87.3 (2004): 96-103.

10. Burton GJ., et al. "Pre-eclampsia: pathophysiology and clinical implications". BMJ 366.12381 (2019).

11. English FA., et al. "Risk factors and effective management of preeclampsia”. Integrated Blood Pressure Control 8.7 (2015).

12. Romero R., et al. "Preeclampsia: a link between trophoblast dysregulation and an antiangiogenic state". Journal of Clinical Investigation 123 (2013): 2775-2777.

13. Youssef GS. "Hypertension in pregnancy”. European Society of Cardiology 17 (2019): 1-8.

14. Ersch J., et al. "Feeding problems in preterm infants of preeclamptic mothers". Journal of Paediatrics and Child Health 44.11 (2008): 651-655.

15. Vikse BE., et al. "Preeclampsia and the risk of end-stage renal disease". The New England Journal of Medicine 21.359.8 (2008): 800-809.

16. Barton JR., et al. "Gastrointestinal complications of pre-eclampsia". Seminars in Perinatology 33.3 (2009): 179-188.

17. https://www.genecards.org/cgi-bin / carddisp. pl?gene=STOX1 
18. Oudejans CBM., et al., "The parent-of-origin effect of 10q22 in pre-eclamptic females coincides with two regions clustered for genes with downregulated expression in androgenetic placentas". Molecular Human Reproduction 10.8 (2004): 589-598.

19. van Dijk M., et al. "Maternal segregation of the Dutch preeclampsia locus at 10q22 with a new member of the winged helix gene family". Nature Genetics 37 (2005): 514-519.

20. van Dijk M., et al. "Differential methylation of STOX1 in human placenta”. Epigenetics 5.8 (2010): 736-742.

21. Lachmeijer, A.M., et al. "Searching for preeclampsia genes: the current position". European Journal of Obstetrics and Gynecology and Reproductive Biology 105 (2002): 94-113.

22. Iglesias-Platas I., et al., "STOX1 is not imprinted and is not likely to be involved in preeclampsia". Nature Genetics 39 (2007): 279-280.

23. Zhao YM., et al. "Correlation between the expression of STOX1 in placenta of patients with early onset preeclampsia". Zhonghиа уі хие za zhi 99.21 (2019): 1664-1668.

24. Pinarbasi E., et al. "STOX1 gene Y153H polymorphism is associated with early-onset preeclampsia in Turkish population". Gene 754 (2020): 144894.

25. Berends AL., et al. "STOX1 gene in preeclampsia and intrauterine growth restriction". BJOG 114.9 (2007): 1163-1167.

26. Kivinen K., et al. "Evaluation of STOX1 as a preeclampsia candidate gene in a population-wide sample". European Journal of Human Genetics 15 (2007): 494-497.

\section{Assets from publication with us}

- Prompt Acknowledgement after receiving the article

- Thorough Double blinded peer review

- Rapid Publication

- Issue of Publication Certificate

- High visibility of your Published work

Website: www.actascientific.com/

Submit Article: www.actascientific.com/submission.php

Email us: editor@actascientific.com

Contact us: +919182824667 